\title{
Effect of Foot Reflexology on Labour Pain and Outcome among Primipara
}

\author{
Fatma Kamal Ali ${ }^{1}$, Nadia Mohamed Fahmi ${ }^{2}$, Soad Abd El Salam \\ Ramadan $^{3}$, Aziza Ibrahim Mohamed ${ }^{4}$ \\ ${ }^{1}$ Assist. Lecturer Obstetrics and Woman's Health Nursing, Faculty of Nursing, Benha \\ University, ${ }^{2}$ Maternity and Neonatal Health Nursing, Faculty of Nursing, Ain Shams \\ University, ${ }^{3}$ Obstetrics and Woman's Health Nursing, Faculty of Nursing, Benha \\ University, ${ }^{4}$ Obstetrics and Woman's Health Nursing, Faculty of Nursing, Benha \\ University
}

\begin{abstract}
Background: Reflexology is a form of complementary and alternative medicine; it has gained popularity in the treatment of various conditions, including labour pain. Purpose: of this study was to assess the effect of foot reflexology on pain severity and outcome of labor among primipara. Hypothesis: primipara who practices foot reflexology in the study group will have less labour pain than those who don't practice in the control group. Also, primipara who practices foot reflexology will have fewer duration of labour than those who don't practice in the control group. A quasiexperimental design was utilized to fulfill the purpose of this study. A Purposive sample of 240 primipara was selected. A simple random sample was done to assign them in to a study group (120 primipara) and control group (120 primipara). Data were collected through three main tools: structured interviewing questionnaire, modified partograph and numeric rating scale. Results: primipara in the study group had fewer duration of the $1^{\text {st }}$, $2^{\text {nd }}$, and $3^{\text {rd }}$ stage of labour $(302.00 \pm 31.06,28.53 \pm 4.47$ and $10.44 \pm 2.05)$ than primipara in the control group $(348.39 \pm 17.81,39.69 \pm 6.33$ and $15.36 \pm 1.69)$. Conclusion: primipara who practiced foot reflexology in the study group had fewer labour pains than primipara who did not practice in the control group. Primipara who practiced foot reflexology in the study group had fewer duration of $1^{\text {st }}, 2^{\text {nd }}$, and $3^{\text {rd }}$ stage of labour than primipara who didn't practice in the control group. Recommendation: foot reflexology is required for primipara at the delivery units.
\end{abstract}

Keywords: Reflexology, pain, Primipara

\section{INTRODUCTION:}

Labor is one of the important events of life experienced by a woman. Fear of labor pain is one of the most important reasons that women do not accept natural vaginal delivery. Active participation of the mother in labor can lead to decreased rate of cesarean and duration of labor without deleterious effects on both the mother and fetus. One of the common factors is the fear and anxiety because of lack of information about labor. In addition, elimination of fear and anxiety not only causes satisfactory labor but also increase motivation to create a good mother and child relationship (Hanjani, et al., 2015).

Management of pain in labour has a beneficial effect on both mother and fetus. The methods used for the management of labour pain are divided into two groups: pharmacological and non-pharmacological methods. The pharmacological methods include analgesia, which decrease the awareness of pain and anesthesia which causes partial or complete loss of sensation, but such drugs has many adverse effects. They may cause maternal hypotension that decreases blood flow to the placenta resulting in fetal hypoxia and acidosis (Goweily, 2015).

On the other hand, non-pharmacological pain methods not only relieve pain, but also relieve fear, anxiety and drug requirement. Moreover, a nonpharmacological method affects the mother as well as baby. Many simple, effective, low cost non-pharmacological 
methods to relieve labour pain can be initiated by nurses with the potential benefits of improved labor progress, reduction in use of medication, improved patient satisfaction and decreases costs. Some of these methods are counter pressure, therapeutic touch, walking, rocking, application of heat and cold, Transcutaneous electrical nerve stimulation (TENS), showers, breathing techniques, listening to music, imaginary, childbirth education and reflexology (Deepak, et al., 2013).

Reflexology is a non-pharmacological method for pain relief. In reflexology, by using pressure on reflexive points of sole and sometimes the palm that is in accordance with each part of the body, the balance returns to all over the body and improves comfort. Reflexologists believe that pressure on certain reflex points of the sole and palm during disease breaks calcium crystals and uric acid accumulated in nerve endings and opens blocked nerve pathways, and improves blood flow in the entire body. During labor, stimulation of pituitary gland, hypothalamus, solar plexus, and uterine decrease pain, anxiety and stress (Hanjani, et al., 2015).

Promoting comfort and controlling pain are two of the most important goals of nursing practice toward woman during labor. Nurses are most effective in managing mother's labor pain if they understand the physiology of pain. Additionally the nurse supports and assists the woman while applying nonpharmacologic interventions for pain relief and relaxation. During labor, the nurse should ask the woman how she feels to evaluate the effectiveness of the specific pain management techniques used. Appropriate interventions can then be planned or continued for effective care, such as trying other nonpharmacologic methods (Abd ElFattah, et al., 2015).

SIGNIFICANCE OF THE STUDY:
Excessive pain during labour can lead to the aggravation of mothers' fear and anxiety, and subsequently decrease uterine contractions and increase labor time and the probability of aided delivery and Caesarean Section. Pain control is an important part of modern Midwifery care (Kamjoo, 2014).

Pharmaceutical measures are often expensive and have harmful effects for reducing labor pain. In the pharmacological methods, the pain feeling would be reduced physiologically but psychological and emotional conditions of the mothers are ignored (Funai, and Norwitz, 2009). So the nurse should help women to become more relaxed through using a nonpharmacological pain relieve measures especially reflexology to relieve pain, enhance relaxation during labour and to free from side effects of analgesics/anesthesia (Hassan, 2011).

\section{PURPOSE:}

This study aims to evaluate the effect of foot reflexology on pain severity and outcome of labor among primipara.

\section{HYPOTHESIS:}

1. Primipara who practices foot reflexology will have less labour pain than those who do not practice in the control group.

2. Primipara who practices foot reflexology will have fewer duration of labour than those who do not practice in the control group.

\section{METHODS:}

The aim of the study was to evaluate the effect of foot reflexology on pain severity and outcome of labor among primipara.

\section{Research design:}

A quasi experimental design was utilized to fulfill the aim of this study. Study and control

\section{Setting:}


This study was conducted at delivery room in obstetrics and gynecological department at benha university hospital. It is a university-affiliated hospital provides obstetrics and gynecology health care service including antenatal care and counseling for family planning, high-risk care and delivery care. The childbirth services unit consists of reception room, room for the first stage of lobar services, vaginal delivery room, cesarean section room and postnatal care room.

\section{Sample:}

- Sample type: Simple random sample

- Sample size: The total number of primipara attending to delivery room at Benha University Hospital at (20132014 year) was 600 primipara (Benha University Hospital Census, 2014). So, expected number of study subjects as calculated by the following formula was 240 .

$$
\mathrm{n}=\frac{\mathrm{N}}{1+\mathrm{N}}(\mathrm{e}) 2
$$

Where:

$\mathrm{n}=$ sample size

$\mathrm{N}=$ population

$\mathrm{e}=$ margin error $(0.05)$

A total 240 woman were randomly divided in to two group (control group= 120 woman who received routine car and study group $=120$ woman who received foot reflexology).

\section{Inclusion Criteria:}

* Primipara women

* No risk women with no medical or obstetrics complications

* Women aged 18-35 years

* Women at the gestational period between 37-42 weeks

\section{Instruments of data collection:}

Four main instruments were used for data collection:-

Instrument (one): Social and obstetrics characteristics structured interviewing questionnaire:

The researcher designed it after reviewing related literature and under guidance of supervisors. It included:

- Part 1- Social characteristics of women, it included (name, age, residence, level of education, occupation, weight, height, body mass index)

- Part 2- Obstetrical history of women, it included (gestational age, last menstrual date, No of pregnancies).

\section{Instrument (two): Modified partograph} for labour progress:

It was adopted from WHO, (2000). The partograph has been used to collect data related to labor progress. This tool included three main parts:

- Part 1- Fetal condition that includes fetal heart rate, color of liquor, and degree of molding

- Part 2- The progress of labour that includes cervical dilatation, descent of head, and uterine contractions

- Part 3- Maternal condition that includes blood pressure, pulse, temperature, and urine analysis for albumen, protein and volume

Instrument (three). Numeric Rating Scale (NRS):

The NRS was adopted from McCaffery, et al., (1989). It was used to assess the pain intensity experienced by the woman during labour. It contained a blank line anchored at each end of the line by adjectives that describe the extremes of pain. To facilitate measurement, a $10 \mathrm{~cm}$ line usually is used. It was graduated from no pain to sever pain.

\section{Pilot study:}

The pilot study was carried out. It involved ten percent of the total sample (24 women) to test the clarity and applicability of the study tools as well as the estimation of the time needed to fill the questionnaire. Women involved in the pilot not excluded from the study.

\section{Tools validity:}


The tools of data collection were submitted to a panel of five nursing experts in the field of obstetrics and genecology to test the content validity. Modification were carried out according to the panel' judgments about the clarity of sentences and appropriateness of content.

\section{Ethical considerations:}

1. Each woman was informed about the purpose and benefits of the study at the beginning of interview and time throughout the study.

2. An oral consent was obtained from each woman before starting data collection.

3. Confidentiality was ensured throughout the study process, where personal data were not disclosed, and the women were assured that all data was used only for research purpose.

4. Each woman was informed that, participation was voluntary and she had the right to withdrawal at any time.

\section{Procedure:}

- The necessary official permissions for data collection were obtained by submitting an official letters issued from the dean of faculty of nursing to administrators of the study setting. The title and objectives of study were illustrated as well as the main data item to be covered.

- Data was collected through a period of one year from the beginning of May 2015 to the end of April 2016 at delivery room in the obstetrics and gynecological department at benha university hospital.

- The researcher attended the labor unit three days per week (Sunday, Tuesday, and Thursday) from $8 \mathrm{am}$ to $3 \mathrm{pm}$ to recruit the sample.

- Primipara who met the inclusion criteria were selected. On admission, the researcher introduced herself and explained the purpose of the research and methods of data collection

- The sample was divided into two groups, the control group (group A) constituted 120 women and the study group (group B) constituted 120 women. The study was started by control group and followed by the study group to avoid contamination of the study.

- Routine care was given to the control group by the hospital staff.

- Initial assessment for the control group:

* Assessing Social and obstetrics characteristics using instrument one (Social and obstetrics characteristics structured interviewing questionnaire).

* Assessing progress of labour using instrument two (the modified partograph)

* Assessing the level of pain using instrument three (NRS)

* The researcher asked questions in Arabic and recorded the answers in the schedule. The initial assessment took around 15 minutes to be completed for each woman.

- After one hour:

* Assessing labour progress and level of pain

- Repeated assessment:

* Pain assessed after 1 hour, at cervical dilatation $6-7 \mathrm{~cm}$ and 8 $10 \mathrm{~cm}$ of the $1 \mathrm{st}$ stage of labour, at the 2nd stage of labour and at the 3rd stage of labour.

* Assessment the progress of labour, fetal condition, and maternal condition by the partograph

- Initial assessment was done for study group as the control group (assessment of Social and obstetrics characteristics, progress of labour, and level of pain).

- Intervention for the study group:

* Study group women were provided a comfortable and 
unconstrained position and were asked to avoid talking during the intervention unless necessary.

* The researcher was applied mild massage on all feet of the woman then pressure was applied to points on feet which correspond to uterus in the body.

* These points are: (1) A point that lies between the fleshy pads under the big toe and next toe. (2) A point that lies just below the centre of the ball of the foot. (3) A half-moon shaped points that lie from where the toes join the foot to the farthest end of the ball of the foot (Sundari, 2011).

(1)

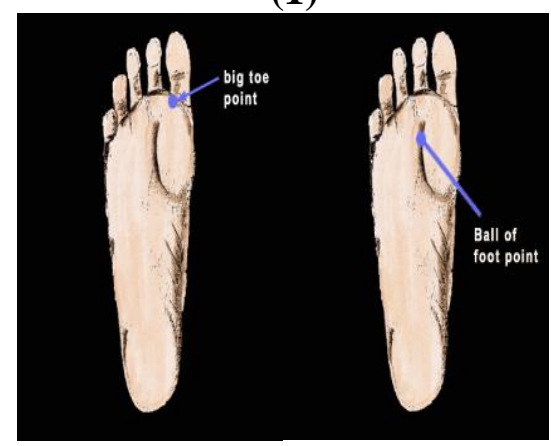

(2)

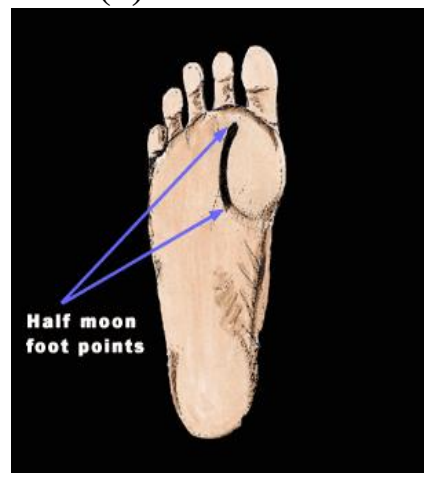

(3)

* When the participants of study group were at a dilation of 4-5 cm (active phase), reflexology was performed by the researcher for 20 minutes on each foot (total 40 minutes for both feet).

* The frequency of massages depended on the frequency of contractions during those 40 minutes (Dolatian, et al., 2011).
* A point (1) that lies between the fleshy pads under the big toe and next toe: The researcher hold one of the woman's feet firmly in their hands and applied strong pressure at the beginning of a contraction with their finger or thumb, easing the pressure off as the contraction finished.

* A point (2) that lies just below the centre of the ball of the foot: Again, on the next contraction the researcher hold one of the woman's feet firmly in their hands and applied strong pressure at the beginning of a contraction with their finger or thumb, easing the pressure off as the contraction finished.

* A half-moon shaped points (3) that lie from where the toes join the foot to the farthest end of the ball of the foot: Again, on the next contraction the researcher wrapped four of their fingers around the ball(s) of the foot, applied pressure during the followed contraction, easing the pressure off as the contraction finished.

* After half-moon shaped points massage was finished, the cycle was repeated in the same foot for 20 minute.

* The cycles of foot reflexology was applied in the second foot as the first foot for 20 minute.

* Then the researcher followed women until after delivery.

- Assessment was done as the control group (initial assessment, after one hour, repeated assessment).

\section{Statistical design:}

Statistical analysis was done using SPSS version 20. Descriptive statistics were applied (e.g., mean, standard deviation, frequency and percentages). Test of significance (t test, chi-square). A statistical significant difference was 
considered when $p \leq 0.05$. In addition, $A$ highly statistical significant difference was considered when $\mathrm{p}<0.01$.

\section{Results:}

Table (1) clarifies that more than half $(55.8 \%$ and $52.5 \%)$ of both study and control groups respectively in age group from (18-22 years) with a mean age of $22.02 \pm 3.03$ and 21.95 \pm 2.68 years respectively. Concerning level of education, it was clear that less than half (45.8\% and $46.7 \%)$ of both study and control groups respectively had university education. In addition, there was no statistical significant difference between study and control groups $(\mathrm{P}>0.05)$.

Table (2) represents the anthropometric measurements of both study and control group, it showed that, the mean weight of both study and control groups were $86.30 \pm 8.69 \mathrm{~kg}$ and $84.85 \pm 8.15 \mathrm{~kg}$ respectively, the mean height of both study and control groups were $162.92 \pm 2.91 \mathrm{~cm}$ and $162.40 \pm 2.63 \mathrm{~cm}$ respectively. In addition, the mean body mass index in both study and control groups were $32.45 \pm 2.56 \mathrm{~kg} / \mathrm{m} 2$ and $32.11 \pm 2.50 \mathrm{~kg} / \mathrm{m} 2$ respectively.

Table (3) clarifies mean scores of the duration of labor throughout the three stages among the study and the control groups. This table indicated that, there was a shorter duration of all stages of labour among study group women with a highly statistically significant difference between study and control groups $(\mathrm{P}<$ $0.001 * *)$.

Table (4) reveals mean scores of vital signs of mothers in the study and control groups during the first stage of Labor. The results indicated that on admission there was no a statistical significant difference between study and control groups regarding vital signs measurements $(\mathrm{P}>0.05)$. for cervical dilatation $(4-7 \mathrm{~cm})$ there was a highly statistically significant difference between study and control groups regarding pulse measurement $\left(\mathrm{P}<0.001^{* *}\right)$, meanwhile there was no a statistical significant difference between study and control groups regarding systolic and diastolic blood pressure and temperature measurements $(\mathrm{P}>0.05)$. With cervical dilatation $(8-10 \mathrm{~cm})$, there was a highly statistical significant difference between study and control groups regarding systolic and diastolic blood pressure and pulse measurement (P <0.001**), whereas, there was no a statistical significant difference between study and control groups regarding temperature measurements $(\mathrm{P}>0.05)$.

Table (5) shows that there was no a statistically significant difference regarding mean of fetal heart rate between study and control groups during first stage of Labor.

Table (6) illustrates mean labor pain scores among study and control groups during the three stages of labour. The result indicated that, there was no statistical significant difference between the study and control groups before intervention. There was a reduction in labour pain scores between primipara in the study group during the first stage of labour (immediately after intervention, at cervical dilatation $6 \mathrm{~cm}$ and at cervical dilatation $8 \mathrm{~cm}$ ) with a highly statistical significant difference between study and control groups $\mathrm{P}<0.001 * *$. On the other hand there was no statistically significant difference between study and control groups related to labour pain during the second and the third stage of labour $(\mathrm{P}>0.05)$.

\section{Table (1): Distribution of the study and control groups according to their social characteristics $(n=240)$}


Effect of Foot Reflexology on Labour Pain and Outcome among Primipara

\begin{tabular}{|c|c|c|c|c|c|c|}
\hline \multirow{2}{*}{$\begin{array}{l}\text { Demographic } \\
\text { characteristics }\end{array}$} & \multicolumn{2}{|c|}{$\begin{array}{c}\begin{array}{c}\text { Control group } \\
n=120\end{array} \\
\end{array}$} & \multicolumn{2}{|c|}{$\begin{array}{c}\text { Study group } \\
n=120 \\
\end{array}$} & \multirow[t]{2}{*}{$\mathrm{X}^{2}$} & \multirow[t]{2}{*}{ P value } \\
\hline & No & $\%$ & No & $\%$ & & \\
\hline \multicolumn{5}{|l|}{ Age in years } & \multirow{5}{*}{3.23} & \multirow{5}{*}{$>0.05$} \\
\hline $18-$ & 63 & 52.5 & 67 & 55.8 & & \\
\hline $22-$ & 45 & 37.5 & 34 & 28.3 & & \\
\hline$\geq 26$ & 12 & 10.0 & 19 & 15.8 & & \\
\hline Mean \pm SD & \multicolumn{2}{|c|}{$21.95 \pm 2.68$} & \multicolumn{2}{|c|}{$22.02 \pm 3.03$} & & \\
\hline \multicolumn{5}{|l|}{ Residence } & \multirow{3}{*}{0.271} & \multirow{3}{*}{$>0.05$} \\
\hline Urban & 54 & 45.0 & 50 & 41.7 & & \\
\hline Rural & 66 & 55.0 & 70 & 58.3 & & \\
\hline \multicolumn{5}{|c|}{ Educational qualification } & \multirow{7}{*}{1.43} & \multirow{7}{*}{$>0.05$} \\
\hline Can't read and write & 4 & 3.3 & 2 & 1.7 & & \\
\hline Read and write & 1 & 0.8 & 2 & 1.7 & & \\
\hline Primary school & 6 & 5.0 & 5 & 4.2 & & \\
\hline Preparatory school & 12 & 10.0 & 15 & 12.5 & & \\
\hline Secondary school & 41 & 34.2 & 41 & 34.2 & & \\
\hline University education & 56 & 46.7 & 55 & 45.8 & & \\
\hline \multicolumn{5}{|l|}{ Occupational status } & \multirow{3}{*}{0.172} & \multirow{3}{*}{$>0.05$} \\
\hline Housewife & 80 & 66.7 & 83 & 69.2 & & \\
\hline Working & 40 & 33.3 & 37 & 30.8 & & \\
\hline
\end{tabular}

Table (2): Mean score of anthropometric measurements

\begin{tabular}{|l|c|c|c|c||}
\hline \multirow{2}{*}{ Parameters } & $\begin{array}{c}\text { Control group } \\
\mathbf{n = 1 2 0}\end{array}$ & $\begin{array}{c}\text { Study group } \\
\mathbf{n = 1 2 0}\end{array}$ & \multirow{2}{*}{ T test } & \multirow{2}{*}{ P value } \\
\cline { 2 - 4 } & Mean \pm SD & Mean \pm SD & & $>0.05$ \\
Weight in kg & $84.85 \pm 8.15$ & $86.30 \pm 8.69$ & 1.33 & $>0.05$ \\
Height in cm & $162.40 \pm 2.63$ & $162.92 \pm 2.91$ & 1.44 & $>0.05$ \\
\hline
\end{tabular}

Table (3): Mean duration of labor throughout the three stages among the study and the control groups $(n=240)$

\begin{tabular}{|l|c|c|c|c|}
\hline \multicolumn{1}{|c|}{ Duration of labour stages } & $\begin{array}{c}\text { Control group } \\
\mathbf{n = 1 2 0}\end{array}$ & $\begin{array}{c}\text { Study group } \\
\mathbf{n = 1 2 0}\end{array}$ & \multirow{2}{*}{ T test } & P value \\
\cline { 2 - 3 } & $\mathbf{M e a n} \pm \mathbf{S D}$ & $\mathbf{M e a n} \pm \mathbf{S D}$ & & \\
\hline Duration of first stage & $348.39 \pm 17.81$ & $302.00 \pm 31.06$ & 14.18 & $<0.001^{* *}$ \\
Duration of the second stage & $39.69 \pm 6.33$ & $28.53 \pm 4.47$ & 15.76 & $<0.001^{* *}$ \\
Duration of the third stage & $15.36 \pm 1.69$ & $10.44 \pm 2.05$ & 20.24 & $<0.001^{* *}$ \\
\hline
\end{tabular}

**A Highly Statistical significant $p \leq 0.001$

Table (4): Mean vital signs of mothers in the study and control groups during the first stage of labor $(\mathbf{n}=\mathbf{2 4 0})$

\begin{tabular}{|l|c|c|c|c|}
\hline Vital signs & Control group & Study group & T test & P value \\
\hline
\end{tabular}


Effect of Foot Reflexology on Labour Pain and Outcome among Primipara

\begin{tabular}{|c|c|c|c|c|}
\hline \multirow[t]{2}{*}{ measurements } & $\mathrm{n}=120$ & $\mathrm{n}=120$ & & \\
\hline & Mean \pm SD & Mean \pm SD & & \\
\hline \multicolumn{5}{|l|}{ On admission } \\
\hline Systolic BP (mmHg) & $123.25 \pm 5.34$ & $122.40 \pm 6.00$ & 1.16 & $>0.05$ \\
\hline Diastolic BP (mmHg) & $77.64 \pm 5.05$ & $76.02 \pm 4.49$ & 2.61 & $>0.05$ \\
\hline Pulse & $75.02 \pm 6.82$ & $73.47 \pm 5.82$ & 1.98 & $>0.05$ \\
\hline Temperature & $37.19 \pm .28$ & $37.22 \pm .27$ & 0.898 & $>0.05$ \\
\hline \multicolumn{5}{|c|}{ With cervical dilatation $4-7 \mathrm{~cm}$} \\
\hline Systolic BP (mmHg) & $123.40 \pm 5.47$ & $120.83 \pm 6.68$ & 3.26 & $>0.05$ \\
\hline Diastolic BP (mmHg) & $76.40 \pm 5.12$ & $76.80 \pm 4.36$ & 0.651 & $>0.05$ \\
\hline Pulse & $84.21 \pm 8.13$ & $70.51 \pm 3.55$ & 16.90 & $<0.001 * *$ \\
\hline Temperature & $37.18 \pm .28$ & $37.17 \pm .26$ & 0.118 & $>0.05$ \\
\hline \multicolumn{5}{|c|}{ With cervical dilatation $8-10 \mathrm{~cm}$} \\
\hline Systolic BP (mmHg) & $123.75 \pm 6.01$ & $120.34 \pm 6.02$ & 4.39 & $<0.001 * *$ \\
\hline Diastolic BP (mmHg) & $77.34 \pm 4.59$ & $75.51 \pm 4.34$ & 3.16 & $<0.001 * *$ \\
\hline Pulse & $81.72 \pm 9.85$ & $71.70 \pm 3.27$ & 10.57 & $<0.001 * *$ \\
\hline Temperature & $37.18 \pm .27$ & $37.18 \pm .25$ & 0.108 & $>0.05$ \\
\hline
\end{tabular}

**A Highly Statistical significant $\mathrm{p} \leq 0.001$

Table (5): Mean of fetal heart rate among study and control groups during first stage of labor $(n=240)$

\begin{tabular}{|c|c|c|c|c|}
\hline \multirow[t]{2}{*}{ FHR measurements } & $\begin{array}{c}\text { Control group } \\
\mathbf{n}=\mathbf{1 2 0} \\
\end{array}$ & $\begin{array}{c}\text { Study group } \\
\mathbf{n}=\mathbf{1 2 0}\end{array}$ & \multirow[t]{2}{*}{ T test } & \multirow[t]{2}{*}{$P$ value } \\
\hline & Mean \pm SD & Mean \pm SD & & \\
\hline On admission & $139.15 \pm 12.87$ & $137.56 \pm 13.40$ & .933 & $>0.05$ \\
\hline \multicolumn{5}{|l|}{ Through intervention } \\
\hline $\begin{array}{l}1^{\text {st }} \text { measure } \\
2^{\text {nd }} \text { measure } \\
3^{\text {rd }} \text { measure }\end{array}$ & $\begin{array}{l}139.05 \pm 12.77 \\
139.40 \pm 13.34 \\
137.46 \pm 13.19\end{array}$ & $\begin{array}{l}136.72 \pm 12.90 \\
141.50 \pm 12.94 \\
136.35 \pm 12.23\end{array}$ & $\begin{array}{c}1.403 \\
-1.243 \\
.675\end{array}$ & $\begin{array}{l}>0.05 \\
>0.05 \\
>0.05\end{array}$ \\
\hline
\end{tabular}

A Statistical significant $p \leq 0.05$

Table (6): Mean labor pain scores among study and control groups during the three stages of labour $(n=240)$

\begin{tabular}{|c|c|c|c|c|}
\hline \multirow[t]{2}{*}{ Labour pain assessment } & $\begin{array}{c}\text { Control group } \\
n=120\end{array}$ & $\begin{array}{c}\text { Study group } \\
n=120\end{array}$ & \multirow[t]{2}{*}{ T test } & \multirow[t]{2}{*}{ P value } \\
\hline & Mean \pm SD & Mean \pm SD & & \\
\hline \multicolumn{5}{|l|}{ First stage of labour } \\
\hline $\begin{array}{l}\text { Before intervention }(4-5 \mathrm{~cm}) \\
\text { Immediately after intervention }(4-5 \mathrm{~cm}) \\
\text { At cervical dilatation }(6 \mathrm{~cm}) \\
\text { At cervical dilatation }(8 \mathrm{~cm})\end{array}$ & $\begin{array}{l}5.21 \pm .72 \\
5.91 \pm .66 \\
8.93 \pm .75 \\
9.58 \pm .52\end{array}$ & $\begin{array}{l}5.25 \pm .81 \\
4.15 \pm .81 \\
7.22 \pm .77 \\
7.25 \pm .83\end{array}$ & $\begin{array}{l}-.336- \\
18.209 \\
17.353 \\
25.77\end{array}$ & $\begin{aligned} &>0.05 \\
&< 0.001 * * \\
&<0.001 * * \\
&<0.001 * *\end{aligned}$ \\
\hline \multicolumn{5}{|l|}{ Second stage of labour } \\
\hline $\begin{array}{l}\text { At cervical dilatation }(10 \mathrm{~cm}) \\
\text { At crowning }\end{array}$ & $\begin{array}{l}9.49 \pm .50 \\
9.66 \pm .49\end{array}$ & $\begin{array}{l}9.48 \pm .60 \\
9.57 \pm .60\end{array}$ & $\begin{array}{c}1.29 \\
0.116\end{array}$ & $\begin{array}{l}>0.05 \\
>0.05\end{array}$ \\
\hline \multicolumn{5}{|l|}{ Third stage of labour } \\
\hline After delivery of fetus & $8.64 \pm .91$ & $8.49 \pm .99$ & 1.21 & $>0.05$ \\
\hline
\end{tabular}

$* *$ A Highly Statistical significant $\mathrm{p} \leq 0.001$

\section{Discussion:}

Non-pharmacological or complementary therapies based on sound research findings are needed to be applied for pain relief strategies during normal vaginal delivery. Reflexology is a mild and noninvasive technique of pain management. Nurses use these strategies to reduce the reception and perception of pain (Davim, et al., 2007).

The present study aimed to evaluate the effect of foot reflexology on pain 
severity and outcome of labor among primipara.

In relation to labor pain among study and control groups during the three stages of labour, the result indicated that, there was no statistically significant difference between study and control groups before intervention with a highly statistical significant difference between them (immediately after intervention $4-5 \mathrm{~cm}$, at cervical dilatation $6 \mathrm{~cm}$ and at cervical dilatation $8 \mathrm{~cm}$ ) $\mathrm{P}<0.001 * *$. On the other hand there was no statistically significant difference between study and control groups related to labour pain during the second and the third stage of labour $(\mathrm{P}>0.05)$.

The result of the present study was in the same line with those of Tiran, et al., (2010), who studied the effect of reflexology on labor pain. The results indicated that, reflexology can facilitate the labor progress through increased uterine contractions, and reduced intensity of the labour pain.

As well as, Goweily, (2015), who studied the efficacy of reflexology on first stage labour pains. Who revealed that there was a significant difference between both reflexology and control groups in term of labour pain intensity. In the reflexology group, the results indicated a significant reduction in the labour pain intensity after the reflexology sessions.

Moreover, Isaac, et al., (2016), who studied the effectiveness of reflexology on pain during first stage of labour among women, revealed that in pre-test among 30 mothers 7 (23\%) had moderate pain, 23 (77\%) had severe pain and no one had mild pain. In post-test, at 0 hour, $14(47 \%)$ had mild pain, 16 $(53 \%)$ had moderate pain and no one had severe pain, at 1 hour 29 (97\%) had moderate pain, $1(3 \%)$ had severe pain and no one had mild pain, and after 2hours $27(90 \%)$ had moderate pain, 3 $(10 \%)$ had severe pain and no one had mild pain.
This improvement was due to touching skin could release of endogenous endorphins of the body and would reduce the stress. Therefore, with stress reduction the pain would consequently reduce. The second reason is that, reflexology could remove the fatigue and anxiety. A third cause, explain that pressure on feet activate large diameter fibers that closed the pain gate, thereby inhibited the transmission of pain (Hughes, et al., 2011).

The result of the present study was in disagreement with Hanjani, et al., (2013), who studied effect of foot reflexology on pain intensity and duration of labor on primiparous. The results clarified that there was no statistical significant difference between both reflexology and control groups related to severity of labor pain before and immediately after intervention ( $p>0.05)$. In addition, the result of the present study differed with Abd ElFattah, et al., (2015), who studied outcomes of foot reflexology on the pain and certain features of the labor for the primiparous women. Who reported that there was a statistical significant difference between both study and control groups at the second stage of labour. The reason of the difference in the obtained results with the presents result was due to the method of implementing the technique.

These findings support present study hypothesis (1) that women who practice foot reflexology will have less labour pain than those who don't.

As regards duration of labor throughout the three stages among the study and the control groups, the result of the present study indicated that, there was a shorter duration of all stages of labour with a highly statistically significant difference between study and control groups $(\mathrm{P}<$ $\left.0.001^{* *}\right)$. The results of the present study agreed with Hanjani, et al., (2012), who evaluated the effect of foot reflexology on the outcomes of labor on Primiparous. The results clarified that the duration of labor in the reflexology 
group significantly was lower than the control group $(\mathrm{P}<0.001)$.

In addition, these findings supported by Abd ElFattah, et al., (2015), the results displayed a shorter duration of all stages of labour with a highly statistical significant difference between both reflexology and control groups regarding the first stage, and a statistical significant difference between the two groups regarding the third stage. Moreover, these findings were in accordance with Hanjani, et al., (2015) who studied the effect of foot reflexology on anxiety, pain, and outcomes of the labor in primigravida women. who reported that reflexology reduced duration of labour among reflexology group.

The progress of labor which reflected by a shorter duration of labor might be due to applying reflexology technique might decreased the adrenaline and nor adrenaline and increased endorphins, and inner oxytocin, would consequently increased uterine muscle contractions and activities and could affect the duration of the labor (Abasi, et al., 2008).

The result of the present study was in disagreement with Mirzaei, et al., (2010), who studied the effect of foot reflexology on duration of labor and severity of first-stage labor pain. The results showed that the labor durations were same in both study and control groups $(\mathrm{p}<0.063)$. In addition, Valiani, et al., (2010), study the effect of reflexology on pain and certain features and outcomes of the labour on primiparous women in Isfahan hospitals. The results showed that mean and standard deviation in length of the second stage of labor in the study subjects of reflexology group and routine care group obtained $40.54+12.49$ minutes and $43.63+14.79$ minutes respectively and the statistically difference was not significant $(\mathrm{p}=0.29)$. Mean and standard deviation in length of the third stage of labor in the study subjects of reflexology group and routine care group were $7.25+2.48$ minutes and
$8.04+3.91$ minutes respectively. ANOVA showed no difference between the two groups in terms of length of the third stage of the labor $(p=0.27)$.

Moreover, the result of the present study differed with Ensiyeh, et al., (2012), who studied the effect of reflexology on relieving the labor pain. The results reported that there were no significant relation between massage of uterus pain place and duration of labor $(\mathrm{p}=0.59)$.

Concerning vital signs of mothers among study and control groups during first stage of labor, the result indicated that on admission there was no a statistically significant difference between study and control groups regarding vital signs measurements $(\mathrm{P}>0.05)$. With cervical dilatation (4-7 $\mathrm{cm})$ there was a highly statistically significant difference between study and control groups regarding pulse measurement $\mathrm{P}<0.001 * *$, while there was no a statistically significant difference between study and control groups regarding systolic and diastolic blood pressure and temperature measurements $(\mathrm{P}>0.05)$.

The current study findings supported by Valiani, et al., (2010)who showed that systolic and diastolic blood pressure and pulse rate in the study subjects was lower the control groups. In addition, the results of the present study were in congruent with Hafez (2014), who demonstrate that there were a statistically significant differences between both groups related to effect of reflexology on vital signs of mothers especially heart rate, and blood pressure throughout the active phase of the first stage of labor. Moreover, these results were also in agreement with Goweily, (2015), who reported that mean pulse rate, systolic \& diastolic BP in the intervention group was lower than the control group.

The improvement of vital signs might be due to that when the reflex points are stimulated, general relaxation created in the body. Following this relaxation, stress messages stopped and sympathetic 
nervous system activity decreased. Therefore, there is an assumption that the women who received reflexology, due to reduction of their anxiety and stress level, had lower blood pressure, heart rate and respiratory rate than those who did not receive it (Moeini, et al., 2011).

The result of the present study was in disagreement with Mirzai, et al., (2009), who study the effect of reflexology on the primiparous women in the Afzalipour Hospital in Kerman, the mean scores of temperature, pulse, systolic and diastolic blood pressure of the mothers in the reflexology and control group had no significant difference after intervention. The reason of the difference in the obtained results with the presents result was due to the method of implementing the technique was differed in both study.

Regarding fetal heart rate measurements among study and control groups during first stage of labor, the result indicated that there was no statistical significant difference regarding mean of fetal heart rate between study and control groups during first stage of Labor at different of measurements. The results of the present study were in agreement with $\mathrm{Hafez}$ (2014), who recorded that there were no statistical significant differences between two groups in relation to fetal heart rate throughout active acceleration of the first stage of labor and throughout active deceleration.

These findings support present study hypothesis (2) that women who practice foot reflexology will have favorite outcome of labour than those who don't.

Conclusion:

Based on the results of the present study it could be concluded that; primipara who practiced foot reflexology in the study group had fewer labour pains than primipara who did not practice in the control group. Primipara who practiced foot reflexology in the study group had fewer duration of 1st, 2nd, and 3rd stage of labour than primipara who didn't practice in the control group.

\section{Recommendations:}

- Foot reflexology technique is recommended as an alternative nonpharmacological method, which can be applied in maternity hospitals.

- All nurses working at labour units should be trained to perform foot reflexology for women during labour

- Further studies need to be performed:

* Further researches on the effect of foot reflexology on pain and outcome of labor, with large sample size to show the effect of reflexology

* Other technique of reflexology such as face and hand can be studied in the future. Their effect on pain and outcome of labour can be compared with this study

\section{References}

Abasi, Z., Abedian, Z., and Fadaii, A., (2008): The Effect of massage on the duration of first stage labor. Arak Medical University Journal. 11(1).

Abd ElFattah, H., Metwaly, S., and Khedr, N., (2015): Outcomes of Foot Reflexology on the Pain and Certain Features of the Labor for the Primiparous Women. Life Science Journal.12 (6)

Davim, R., Vasconcelos, G., and Melo, E., (2007): Non-pharmacological strategies on pain relief during labor: pre-testing of an instrument. Revista LatinoAmericana de Enfeermagem. 15(6) [PubMed]

Deepak, Avinash, K.R., and Seema, C., (2013): Effect of Acupressure on Intensity on Labour Pains and Duration of First Stage of Labour among Primigravida Mothers. Nursing and Midwifery Research Journal. 9(4):1-9.

Funai, E.F., and Norwitz, E.R., (2009): Management of normal labor and delivery. Available from: URL: http://www.uptodate.com/. Accessed Oct, 20 2015, 12 Pm.

Goweily, M., (2015): Efficacy of Reflexology on First Stage Labour Pains. Journal of Health, Medicine and Nursing . ISSN 2422-8419 An 
International Peer-reviewed Journal. $18(1)$.

Hafez, O.D., (2014): Effect of reflexology relaxation technique regimen on pregnancy outcome among pregnant women with cardiac disease. B.Sc.Nursing. Faculty of Nursing. Cairo University.

Hanjani , S.M., Torzani, Z.M., Shoghi , M., and Ahmadi, G., (2013): effect of foot reflexology on pain intensity and duration of labor on primiparous. Journal of Semnan University of Medical Sciences. 14(2): 166-171.

Hanjani, S.M., Tourzani, Z.M., and Shoghi, M., (2015): The Effect of Foot Reflexology on Anxiety, Pain, and Outcomes of the Labor in Primigravida Women. Tehran University of Medical Sciences. 53(8):507-511.

Hughes, C.M., Krisnakriengkrai, S., Kumar, S., and McKonough, S.M., (2011): Journal of alternative therapies in health and medicine, 17(3):32-7.

Isaac, S., Magarani, W., and Shalini, D., (2016): Effectiveness Of Reflexology on Pain During First Stage of Labour Among Primigravida Mothers. International Journal of Medicine and Health Profession Research. 3(1): 37 40.

Kamjoo, A., (2014): The effect of reflexology on pain intensity and duration of labor in primipara women. IRCT2014043017503N1

McCaffery, M., Beebe, A., et al. (1989): Pain: Clinical manual for nursing practice, Mosby ST. Louis, MO.

Mirzaei, F., kaviani, M., and peyman, J., (2010): Effect of Foot Reflexology on
Duration of Labor and Severity of FirstStage Labor Pain. Iranian Journal of Obstetrics, Gyneocology and Infertility.13(1):27-32.

Mirzai, F., Kaviani, M., and Jafari, P., (2009): Effects of foot reflexology on pain intensity and duration of first stage labor. The Iranian Journal of Obstetrics, Gynecology and Infertility. 13 (1) [Persian]

Moeini, M., Kahangi, L.S., Valiani, M., and Heshmat, R., (2011): The effect of reflexotherapy on patients' vital signs before coronary artery bypass graft surgery. Iran J Nurs Midwifery Res. 16(1): 8-12.

Sundari, G.D., (2011): Effectiveness of Foot Reflexology on Reduction of Pain and Duration of Labour during First Stage of Labour among Primigravida Mothers in Selected Hospitals, Hassan, Karnataka. Master of Science in nursing, OBG Nursing, College of Nursing, B.M. Road, Hassan, Karnataka.

Tiran, D., Jennifer, A., McNeill Fiona, A., Alderdice, and McMurray, F., (2010): A retrospective cohort study exploring the relationship between antenatal reflexology and intranatal outcome. Top of from

Valiani, M., Shiran, E., Kianpour, M., and Hasanpour, M., (2010): Reviewing the effect of reflexology on the pain and certain features and outcomes of the labor on the primiparous women. Iran $\mathbf{J}$ Nurs Midwifery Res. 15(1):302-310.

World Health Organization (WHO), (2000): World Health Organization Partograph in mangement of labour; 343;1399-1404. 